\title{
Review on Laminated Busbars used in High Frequency Inverters
}

\author{
Chirisavada Jagadeesh ${ }^{l,}$, Gajala Himavarsha ${ }^{2}$ and Bobba Phaneendra Babu ${ }^{1}$ \\ ${ }^{1}$ Department of Electrical Engineering, GRIET, Hyderabad, Telangana, India \\ ${ }^{2}$ Department of Electrical Engineering, GRIET, Hyderabad, Telangana, India \\ ${ }^{3}$ Department of Electrical Engineering, GRIET, Hyderabad, Telangana, India
}

\begin{abstract}
Improvement in the efficiency and cost in the high frequency inverter will play a major role in its applications like electrical vehicles (EV). A high voltage IGBTs are used in inverters to bear the voltage peaks across the IGBT switch at the turning off period of switch. By decreasing the value of voltage peak, can reduce the voltage rating of IGBT switch, by which the system cost will decrease. Decreasing the value of voltage peak can be achieved by decreasing the inductance of the inverter circuit which includes turned on switch inductance, DC link capacitors inductance and connecting wires inductance. By replacing the connecting wires with a laminated busbar in an inverter, the inductance value of a connecting wires can be reduced. Laminated bus bar is a parallel conductor plates separated by a dielectric medium. Upper plate is considered as positive plate and lower plate is a negative plate. In this paper it gives a detailed information about laminated busbar with different designs, using different conductive materials, their calculated inductance in ANSYS 3D FEM software and concluding with suitable laminated busbar for high frequency inverter.
\end{abstract}

\section{Introduction}

Laminated busbar is a device used to reduce or include the inductance in the power electronic circuits. By using it, there will be an improvement in the losses of power electronic circuits. Research up on it was started in 1996 and going on at present in its improvement. It is used in an inverter as the replacement of connecting wires. By this there will be a reduction in inductance which will result in reduction in losses of an inverter. Laminated busbar is used to avoid the circulating currents in parallel connected switching devices in power electronic circuits. It also has wide applications in solar energy and wind energy collection and distribution, because of its low inductance characteristics. It has a major application in electrical vehicles.

This paper is majorly discussing about the inverter application of replacing the connecting wires. Inverter circuit shown in figure $1(\mathrm{a})$, shows the $\mathrm{H}$ - bridge type single phase inverter. It will converts input DC power to a AC power as an output. When the switches $\mathrm{Q}_{1}$ and $\mathrm{Q}_{4}$ of the $\mathrm{H}$-bridge inverter receives triggering pulses, they start conducting and a positive voltage appear across the load. As soon as the IGBT switches $\mathrm{Q}_{2}$ and $\mathrm{Q}_{3}$ receives the triggering signal, IGBT switches $\mathrm{Q}_{1}$ and $\mathrm{Q}_{4}$ will turn off by a peak voltage $\left(\mathrm{V}_{\mathrm{p} 1}\right)$ [1] appeared across the switch as shown in the figure1(b) and given in equation 1.

$$
\mathrm{V}_{\mathrm{P} 1}=\mathrm{V}_{\mathrm{dc}}+1_{1}(\mathrm{di} / \mathrm{dt}) \text {. }
$$

$$
1_{1}=1_{\mathrm{s}}+1_{\mathrm{bc}}+1_{\mathrm{ca}} \text {. }
$$

Where, $1_{\mathrm{s}}$ is a connecting wires inductance of the $\mathrm{H}$ bridge inverter, $l_{\mathrm{bc}}$ is an internal inductance of IGBT switch $\mathrm{Q}_{1}$ of an $\mathrm{H}$ - bridge inverter and $\mathrm{l}_{\mathrm{ca}}$ is an internal inductance of switch $\mathrm{Q}_{2}$.

IGBT switches $\mathrm{Q}_{2}$ and $\mathrm{Q}_{3}$ conducts and a negative voltage appears across the load. Again as the triggering pulses received by the IGBT switches $\mathrm{Q}_{1}$ and $\mathrm{Q}_{4}$, switches $\mathrm{Q}_{2}$ and $\mathrm{Q}_{3}$ will turn off. Peak voltage $\mathrm{V}_{\mathrm{P}_{2}}[1]$ will appears across the IGBT switches $\mathrm{Q}_{2}$ and $\mathrm{Q}_{3}$ as shown in figure 1 (b) and given in equation 3 .

$$
\begin{aligned}
& \mathrm{V}_{\mathrm{P} 2}=\mathrm{V}_{\mathrm{dc}}+1_{2}(\mathrm{di} / \mathrm{dt}) . \\
& 1_{2}=1_{\mathrm{s}}+1_{\mathrm{bd}}+1_{\mathrm{da}} .
\end{aligned}
$$

Where, $l_{b d}$ is an internal inductance of $Q_{3}$ of an $\mathrm{H}-$ bridge inverter, $1_{\mathrm{da}}$ is an internal inductance of switch $\mathrm{Q}$.

It is clear that, to reduce the voltage rating of an IGBT switch in an inverter, there should be reduction of peak voltage occurring across the switches. From the equations $1,2,3$ and 4, we can conclude that the peak voltage occurring across the switch depends on the inductance value of connecting wires and inductance of the IGBT switches. Considering the inductance circuit given in equation 2 as an current path 1 (CP1) and equation 4 as current path2 (CP2). Replacing the connecting wires with laminated busbar can reduce the inductance in the inverter circuit by which, there will be a decrement in its losses. Other advantages of laminated bus bar are increasing of capacitance value of the circuit, improvement in thermal

\footnotetext{
* Corresponding author: author@e-mail.org
} 
stability, no more wiring errors and it allows denser packaging.

This paper consists of detailed explanation with equations of an inverter, by which we can come to know the importance of laminated bus bar. Mentioning the obtained parameter values of two layers laminated bus bar with different materials and designs, simulted in ANSYS 3D FEM software. Representing the simulation results of three layer laminated bus bar, obtained in ANSYS 3D FEM software. Concluding with a best suitable laminated bus bar for a high frequency inverter.

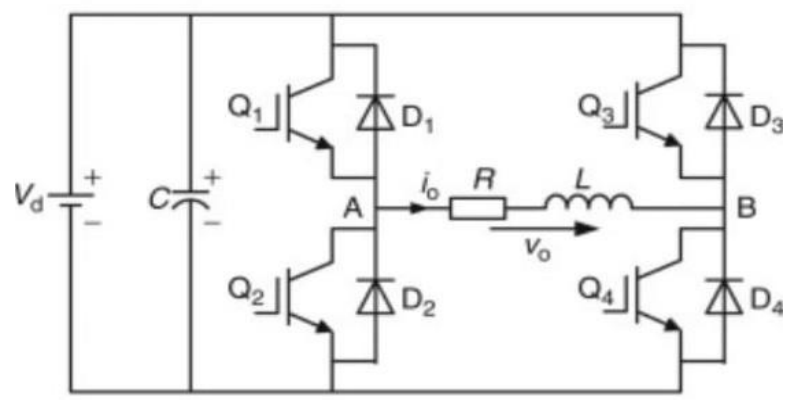

Fig. 1(a). Inverter circuit

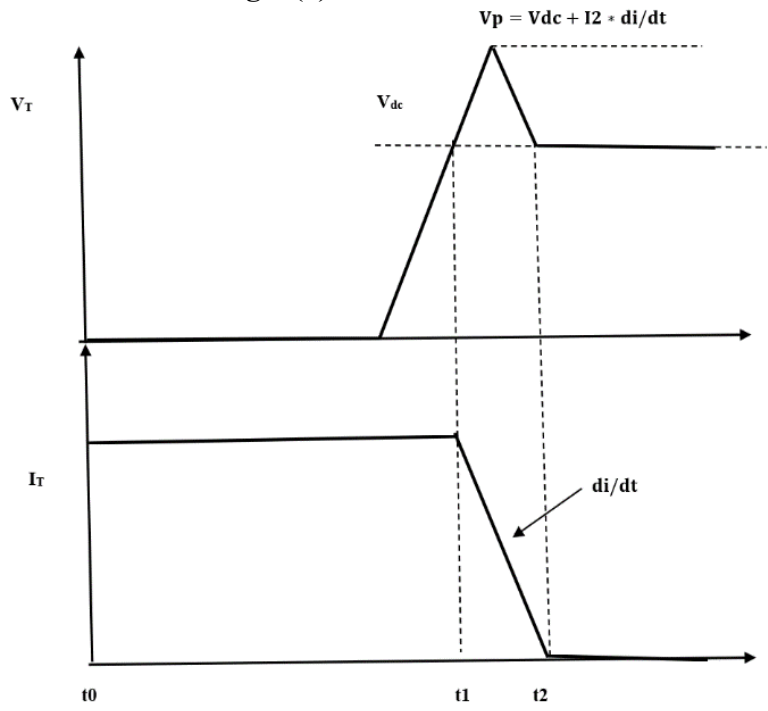

Fig.1(b). Turn off voltage and currents of IGBT

\section{Comprehensive analysis of laminated busbar}

Laminated busbar is a conductor plates seperated by a dielectric medium. Depending up on the number of layers, there are three types of laminated busbar.

1. Two- layer laminated busbar.

2. Three- layer laminated busbar.

3. Multi layers laminated busbar.

Replacing the circular cross section connecting wires to a plates, there are following benefits.

1. Calculating and adjusting the inductance value of a connecting wires will become more easier.
2. Equal distribution of current is possible by which the thermal effect also improves.

3. Making connections will become a bit easier and stronger.

Placing of an laminated busbar in an inverter prototype is shown in figure2[16]. All the IGBT switches, DC link capacitor, cooling system for an IGBT switches, gate controlling drive and all other parts of an inverter are connected to slots provided in laminated busbar. Input DC power should connected to the DC terminals provided at the right side of the busbar and load is connected at the left side AC power collector terminals provided in the busbar.

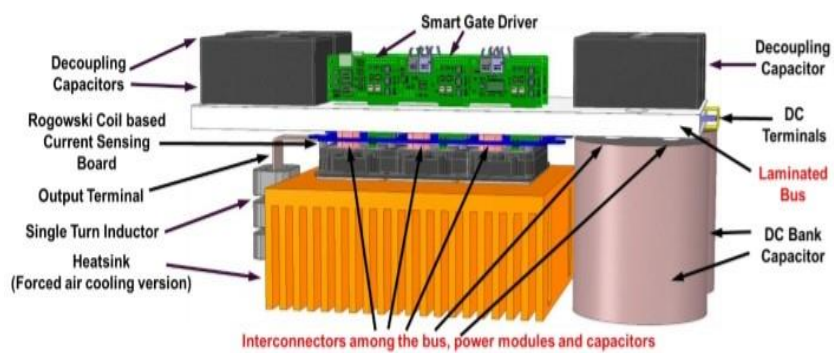

Fig .2. Prototype 3 D drawing

\subsection{Two-layer laminated busbar:}

It consists of two layers of conductors are separated by a dielectric medium. Conductors of laminated busbar are made in a shape of plate. Different devices of inverter like IGBT switch, capacitors, input and output connections are connected to the laminated busbar to make it a complete inverter. By adjusting the dimensions of laminated busbar can change the inductance value of it. Considering some dimensions of laminated busbar as length(1) of $400 \mathrm{~mm}$, breadth (b) of $400 \mathrm{~mm}$ and thickness(t) as $2 \mathrm{~mm}$ to obtain inductance value using ANSYS 3D FEM software.

To consider only the inductance of $\mathrm{CP} 1$ and $\mathrm{CP} 2$, flowing current through positive plate of laminated busbar

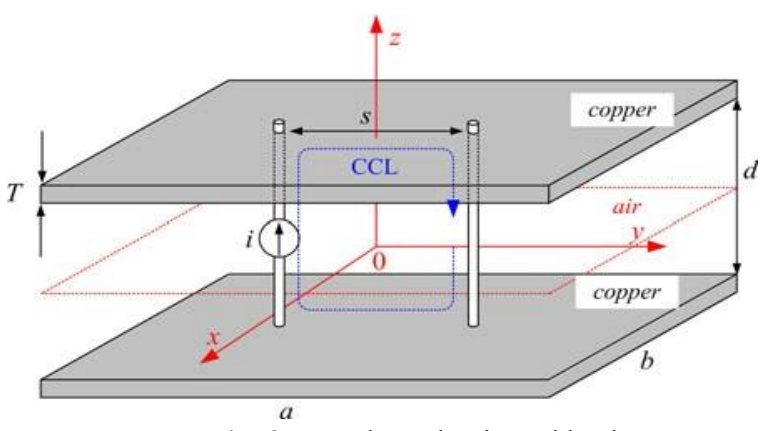

Fig. 3. Two-layer laminated busbar.

only for 's' distance and also return path as negative plate of 's' distance as shown in figure 3. Inductance value of laminated busbar as the distance 's' changes is given in table1[1]. Relation between dimensions of laminated busbar and it's self inductance $\left(1_{\text {self }}\right)$ and mutual inductance $(\mathrm{M})$ is given in equation 5 and 6 [4]. 


$$
\begin{aligned}
& \mathbf{L}_{\text {self }}=2 * 10^{-7}\left[2.303 \log \left(\frac{2 l}{b+t}\right)+2.5+\right. \\
& \left.0.2255\left(\frac{b+t}{l}\right)\right] \\
& \mathbf{M}=\frac{\mu_{r}}{2 \pi}\left(\operatorname{lln} \frac{\sqrt{d^{2}+l^{2}}+l}{\mathrm{~d}}-\sqrt{d^{2}+l^{2}}+d\right)
\end{aligned}
$$

Inductance of laminated busbar for different values of distance between the positive and negative plate of it is given in table 2[1].

Table1. Inductance of laminated busbar for different s values

\begin{tabular}{|l|l|}
\hline $\mathrm{S}(\mathrm{mm})$ & $\mathrm{L}(\mathrm{nH})$ \\
\hline 25 & 3.40 \\
\hline 50 & 4.95 \\
\hline 75 & 5.17 \\
\hline 100 & 5.75 \\
\hline 125 & 6.40 \\
\hline 150 & 7.03 \\
\hline
\end{tabular}

Table2. Inductance of laminated busbar for different $d$ values

\begin{tabular}{|l|l|}
\hline$d(\mathrm{~mm})$ & $\mathrm{L}(\mathrm{nH})$ \\
\hline 1.00 & 5.75 \\
\hline 1.50 & 7.90 \\
\hline 2.00 & 9.93 \\
\hline 2.50 & 12.00 \\
\hline 3.00 & 14.00 \\
\hline 3.50 & 16.20 \\
\hline 4.00 & 18.06 \\
\hline
\end{tabular}

Laminated busbar with different conducting materials and different insulating materials are used and obtained the inductance value in ANSYS 3D FEM software is given in table3[2]. Dimensions of it had considered as length $(\mathrm{l})=300 \mathrm{~mm}$, breadth $(\mathrm{b})=75 \mathrm{~mm}$, thickness $(\mathrm{t})=1.03 \mathrm{~mm}$ and simulated with equal current distribution as shown in figure 5 .

Table3. Inductance of laminated busbar for different materials

\begin{tabular}{|l|l|l|l|l|}
\hline \multirow{2}{*}{$\begin{array}{l}\text { Conductor } \\
\text { materials }\end{array}$} & \multicolumn{4}{|c|}{$\begin{array}{l}\text { Insulating materials used as dielectric medium } \\
\text { (Thickness of Insulator) }\end{array}$} \\
\cline { 2 - 5 } & $\begin{array}{l}\text { Nomex } \\
(1.032 \mathrm{~mm})\end{array}$ & $\begin{array}{l}\text { Epoxy glass } \\
(1.032 \mathrm{~mm})\end{array}$ & $\begin{array}{l}\text { Kapton } \\
(1.030 \mathrm{~mm})\end{array}$ & $\begin{array}{l}\text { Mylar } \\
(1.03016 \mathrm{~mm})\end{array}$ \\
\hline Copper & $\mathrm{L}=7.97 \mathrm{nH}$ & $\mathrm{L}=8.72 \mathrm{nH}$ & $\mathrm{L}=8.67 \mathrm{nH}$ & $\mathrm{L}=7.584 \mathrm{nH}$ \\
\hline Aluminium & $\mathrm{L}=7.5 \mathrm{nH}$ & $\mathrm{L}=8.79 \mathrm{nH}$ & $\mathrm{L}=7.512 \mathrm{nH}$ & $\mathrm{L}=7.97 \mathrm{nH}$ \\
\hline Gold & $\mathrm{L}=7.56 \mathrm{nH}$ & $\mathrm{L}=8.69 \mathrm{nH}$ & $\mathrm{L}=7.582 \mathrm{nH}$ & $\mathrm{L}=7.59 \mathrm{nH}$ \\
\hline
\end{tabular}

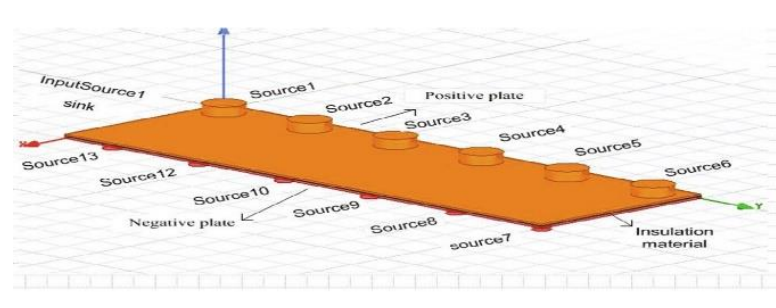

Fig .4. Excitation model of the laminated busbar

\subsection{Three layers laminated bus bar:}

It consists of three layers seperated by a two dielectric medium. Construction of three layer laminated busbar is shown in figure3. Upper layer C\&D are seperated and connected to the output AC terminals of the inverter, layerA and layerB is connected to the positive and negative terminals of the DC power respectively.

Layer C

Layer D

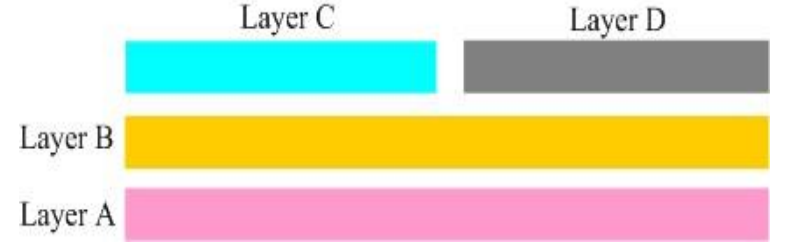

Fig. 5. Cross section of the three-layer busbar
CP1 and CP2 given in equation $2 \& 4$ will change its distance and shape of the path in three layers laminated bus bar. Side view of three layer laminated busbar from layer'C', paths CP1 and CP2 is shown in figure6(a) as path $\mathrm{P} 1$ and $\mathrm{P} 2$. Paths from the side view of layerD is different from it and is shown in figure 6(b). Inductance in this path P4 is increasing due to passing the current through two dielectric mediums. Due to this there is a inequality inductance in the busbar
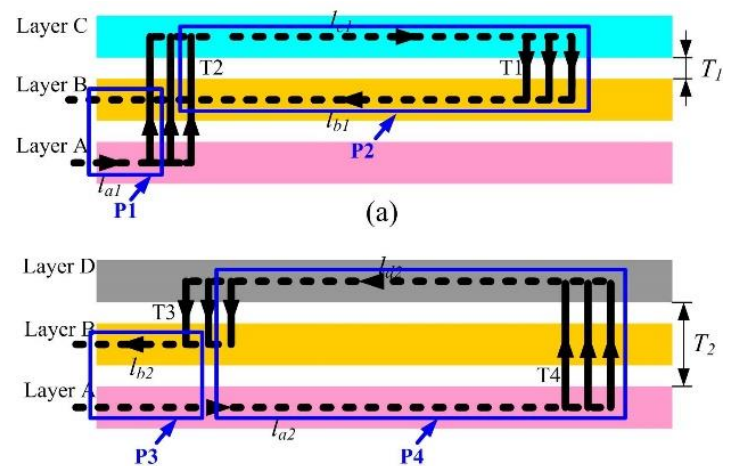

(b)

Fig.6. Commutation loops' insulation thickness: (a) loop1, (b) loop2. 
To avoid this problem, a modified three layer laminated busbar is obtained in which the layers $\mathrm{B}$ and $\mathrm{CD}$ are exchanged. CP1 and CP2 for modified busbar is shown in figure $6 \mathrm{a}, \mathrm{b}$, side views of busbar. Simulation inductance results for non modified modified laminated busbar is given in table4[3].

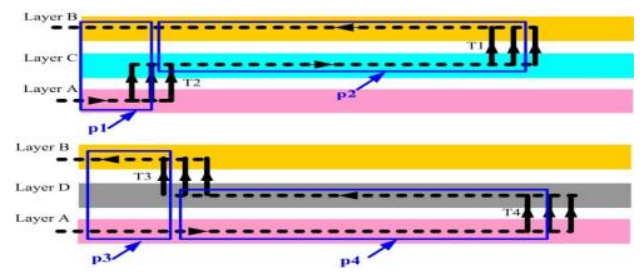

Fig.7. Optimized busbar commutation loops.

Table4. Difference between modified and modified inductance of three layer laminated bus bar.

\begin{tabular}{|l|l|l|l|}
\hline \multicolumn{2}{|l|}{$\begin{array}{l}\text { Three layers laminated } \\
\text { busbar. }\end{array}$} & \multicolumn{2}{|l|}{$\begin{array}{l}\text { Modified three layers } \\
\text { laminated busbar. }\end{array}$} \\
\hline $\mathrm{L}_{\mathrm{CP} 1}(\mathrm{nH})$ & $\mathrm{L}_{\mathrm{CP} 2}(\mathrm{nH})$ & $\mathrm{L}_{\mathrm{CP}}(\mathrm{nH})$ & $\mathrm{L}_{\mathrm{CP} 2}(\mathrm{nH})$ \\
\hline 6.032 & 8.81 & 6.684 & 6.685 \\
\hline
\end{tabular}

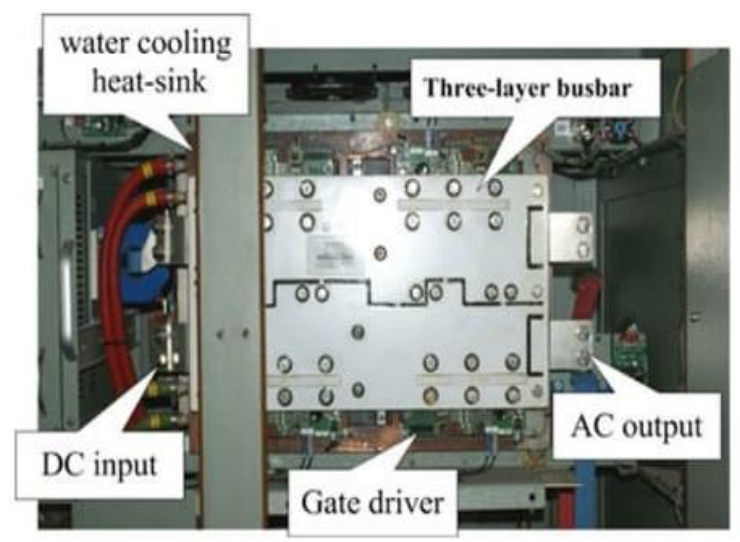

Fig. 8. Three-layer laminated busbar

Prototype of three layer laminated busbar is given in figure 8[1]. It consists of DC input connections to the left side and AC output terminals are at right side, which are connected to the load.

\subsection{Multi layer laminated busbar}

Multi layer laminated busbar consists of number of conductor layers of different materials (copper, aluminum, gold) separated by an insulating materials. In this type of busbar, each layer can be considered for different power supply terminals as shown in figure 9 [16]. It is mainly used for large circuits in which there are many number of electronics devices with high currents. Multi layer laminated busbar will have improvement characteristics than that of other laminated busbar in high currents working circuits. Prototype multi layer laminated busbar for three phase inverter application is shown in figure 10 [16] with supply terminals. All the devices of three phase inverter are connected in the slots provided in laminated busbar. It is best suitable for high power electronic converters

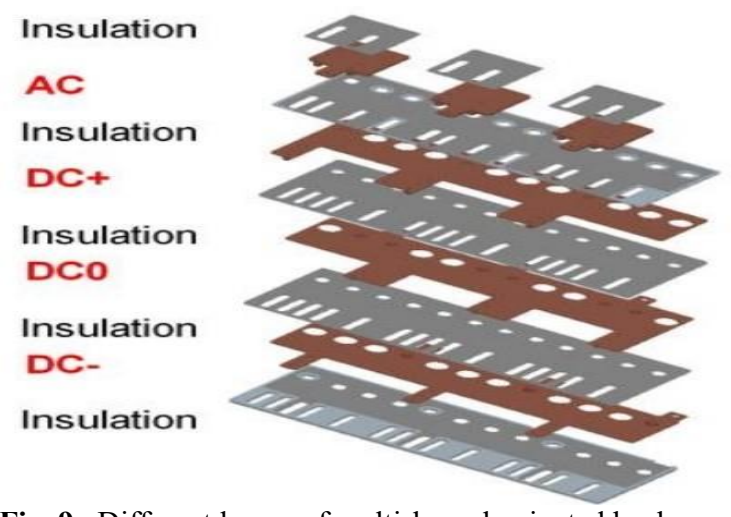

Fig. 9. Different layers of multi-layer laminated busbar

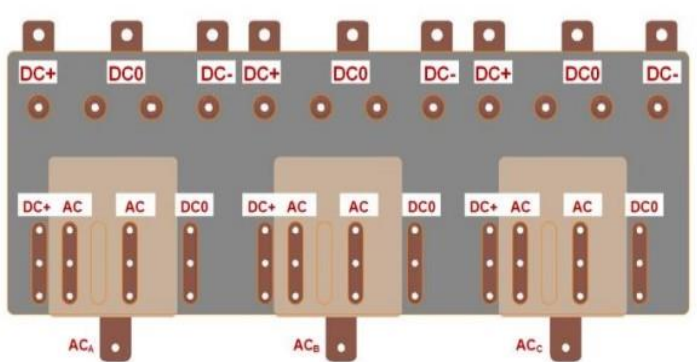

Fig.10. Prototype multi-layer laminated bus bar

From table 1and2, it is clear that inductance of the laminated busbar will be low for air as a dielectric medium. Table 2 and 3 concludes that laminated busbar can obtain a less inductance with less distance between the two plates(d). By changing the materials of conductor, there will be a very less amount of decrement in inductance. By this we can conclude that, by using other materials like aluminium and gold there will decrement in running cost of an inverter for a long time but there is an increment in intial cost of an inverter.

High frequency inverter will operate in a high frequencies which will create a problem of skin effect in the circular cross section wire. Replacing circular cross section wires with a rectangular cross section plates will reduce the power losses in high frequency inverter. From table 1,2,3 and 4 , it is clear that a three layer laminated busbar will maintain a low inductance and reduces the losses, cost and increase in efficiency of high frequency inverters.

\section{Conclusion}

This paper has a detailed information of each type of laminated busbar. Two-layer laminated busbar with different conductor layers and insulating materials was analyzed and mentioned the results obtained by different researchers and compared it. Three layers laminated busbar of modified and non modified details with simulation results obtained in ANSYS 3D FEM software was mentioned, which was referred from the related reference papers. Details of multi layer laminated busbar was mentioned and compared all the types of laminated 
busbar. Finally concluded that a modified three layer laminated is suitable busbar for a high frequency inverter. We can workout in future on inductance reduction in large circuit inverters by modifying a multi layer laminated busbar.

\section{References}

1. C. Chen, X. Pei, Y. Chen, Y. Kang, Investigation, Evaluation and Optimization of stray inductance in laminated busbar, (2014)

2. R. Karthik rao, B. Phaneendra babu, T. Suresh kumar, K. Satyanarayana, Feasibility analysis of different conducting and insulation materials used in laminated bus bars, (2020)

3. C. Chen, X. Pei, Y. Shi, X. Lin, X. Liu, Y. Kang, Modeling and Optimization of high power inverter three-layer laminated busbar,(2012)

4. K. Mariam, P. Magne, B. Bilgin, W. Sanjaka,E. Ali , Laminated busbar design criteria in power converter for electrified power train applications,(2014)

5. Tummala Suresh Kumar, Kosaraju Satyanarayana, Materials Today: Proceeding, 26 (2), 3228-3233, (2020).

6. H. Wen, W. Xiao, Design and Optimization of laminated busbar to reduce transient voltage spike, (2012)

7. O. Puigdellivol, S. Meresse, Y.L. Menach, S. Harmand, J. Francois, Wecxsteen, Thermal topology optimization of a three layer laminated busbar for power converters, (2016)

8. D. Amol ,F. Luo, Multi layer busbar design for a Si IGBT and Sic MOSFET hybrid switch based 100KW three level T-Type PEBB, (2017)

9. J. Wang, S. Yu, X. Zhang, Effect of key physical structure on the laminated busbar inductance, (2016)

10. M.A. James, Laminated busbar for power system interconnects, (1996)

11. K. Matsubara, K. Wada, Current balancing for parallel connecting of silicon carbide MOSFETs using bus bar integrated magnetic material, (2019)

12. X. Yue, F. Xianyong, W. Jun, G. Chaofei, B. Rolando, B. Dushan, E.H Robert, Medium voltage $\mathrm{SiC}$ based converter laminated bus insulation design and assessment, (2019)

13. X.L. Bin, P. Volker, H. Junzhu, W. Haimeng, R.T. Naayagi, K. Wei, L. Sizhuo, Determination of stray inductance of low inductive laminated planar multipost busbars using vector synthesis method, (2019)

14. S. Qiang, W. Wei, Z. Shuo, L. Yiting, A. Mukhtiar, The analysis of power losses of power inverter based SiC MOSFETs, (2019)

15. Y. Zhao, P. Hongwu, D. Amol, N. Balaji, E. Asif Imran, L. Fang,C. Cai, Design and evaluation of laminated busbar for 3-level T-Type NPC power electronics building block with Enhanced dynamic current sharing, (2019)

16. W. Zhongjing, W. Yuheng, M. Mohammad Hazzaz, Y. Zhao, Z. Yue, H. Alan MantoothZ, Busbar design and Optimization for voltage overshoot mitigation of a silicon carbide high-power three-phase T-Type inverters, (2020)

17. L. Bo, L. Weijie, M. Dongyi, D. Lijian, M. Yingtao, Q. Tengfei, D. Lijun,

18. Low stray inductance optimized design for power circuit of Low stray inductance optimized design for power circuit of SiC-MOSFET- based inverter, (2020)

19. Z. Lounis ,B. Davat, Minimization of wiring inductance in high power IGBT inverter, (2000)

20. M.A. Vogelsberger, T. Wiesinger, H. Ertl, Life cycle monitoring and voltage managing unit for DC- link electrolytic capacitors in PWM converters, (2011)

21. F Srinivas Rao J., Srinivasa Varma, P., Suresh Kumar. T, International Journal of Power Electronics and Drive Systems, vol.9, no.3, pp : 1202-1213, (2018).

22. B. Gultekin, M. Ermis, Cascaded multilevel converter-based transmission STATCOM : system design methodology and development of a $12 \mathrm{KV}+/$ 12MVAr power stage, (2013)

23. L. Popova, T. Musikk a, R. Juntunen, M. Lohtander, P. Silventoiner, O. Pyrhonen, J. Pyrhonen, Modeling of low inductive busbar for medium voltage threelevel NPC inverter, (2012)

24. J. Guo, H. Ge, J. Ye, A. Emadi, Improved method for MOSFET voltage rise-time and fall-time estimation in inverter switching loss calculation, (2015)

25. Y. Jiao, S. Lu, F. C. Lee, Switching performance optimization of a high power high frequency three level active neutral point clamped phase leg, (2014)

26. S. Kouro.et al, Recent advances and industrial applications of multilevel converters, (2010) 